\title{
Understanding the Public Perception and Satisfaction of a UK Police Constabulary
}

Imran Awan', Michael Brookes², Monique Powell ${ }^{3}$ and Sarah Stanwell ${ }^{4}$.

\section{Abstract}

This study explores the public perception of a community in Britain, towards a police constabulary in the UK. The study sought to explore how the levels of satisfaction between Black and Minority Ethnicities (BME) and non BME communities towards this police force in the UK. Using a mixed-methods approach, data was obtained by the use of self-completion questionnaires of 112 participants in an area in the UK and the use of a total of 31 semistructured interviews. The findings show that participants questioned police competence, the duty of police officers, policing conduct in relation to investigations, experiences of prejudice and expectations communities have of the police. The results for this study showed that there is some support for the idea that the perception of the police during the first contact with a member of the public is likely to be the most powerful predictor of future opinions on the police. This comes from the idea that the public are concerned not only with what the police do in the community, but how they do their work. Finally, as the current study is concerned with policing the local communities, it is important to remember that members of the community will respond positively to being included in police procedure deliberations and audits. The findings suggest that there is still much work to be done by the police service in order to improve the relationship with the communities that they serve. We argue much more emphasis should be placed on community work and increased engagement with younger people in schools and the wider general public.

Key Words: Policing; Communities; Trust; Discrimination; Black and Minority Ethnicities; Confidence

\footnotetext{
1 Dr Imran Awan, Associate Professor in Criminology and Deputy Director, Centre of Applied Criminology, Birmingham City University

2 Professor Michael Brookes OBE, Professor of Forensic Psychology and MSc Forensic Psychology Programme Leader, Birmingham City University

3 Monique Powell, MSc Forensic Psychology, Birmingham City University, Monique Powell monique powell@hotmail.co.uk

4 Sarah Stanwell, MSc Forensic Psychology, Birmingham City University, Sarah Stanwell Sarah.Stanwell@mail.bcu.ac.uk
} 


\section{Introduction}

There are 43 local police forces in England and Wales and 129,584 full-time equivalent (FTE) police officers (Home Office, 2013). This paper is based on a research study undertaken between June and August 2015 within an area in the UK that draws upon interviews with members of the Black and Minority Ethnic (BME) and non-Black and Minority Ethnic (BME) communities. The study investigated the levels of satisfaction among BME and non-BME groups based on their experiences with one police constabulary in England. For reasons of anonymity and confidentiality we have removed the names of the specific police force and the area where the study took place in the UK. This study was commissioned by the specific police constabulary with the objective of exploring further, previously established levels of dissatisfaction within an area of the UK, towards the specific police force in question. In doing so it links with previous research undertaken by this specific police force, into the satisfaction of those from a BME background with levels of service provided by this police constabulary. In responding to victims of violent incidents, research produced by the specific police force, found that those least satisfied with their services tend to be those between the ages of 25 and 34, and from a black and minority ethnic background, whilst those aged 55 and over from the wider community are most satisfied with the police service.

Drivers of satisfaction include the way in which an incident is investigated, that it was taken seriously and action had been taken in accordance with victim expectations. Previous research conducted by Awan et al. (2013) have found that the impact of poor police community relations are often built upon pre-set attitudes and pre-existing opinions of the police. Their research found that if the police were positively engaging with communities, this would lead to improved levels of trust between the police and BME communities. This also led to increased levels of trust and enhanced police legitimacy. Indeed, their study found that this could impact with BME communities' choice of career with the police service. Specifically, the aim of our study was to:

- To examine the perception of BME communities towards the specific police force in question.

- To examine how best to reach otherwise 'hard to reach groups' in an area in the UK.

- To examine any difference in victim satisfaction between groups (based on any demographic variable such as ethnicity, age, gender, location and interactions) between these by crime type? 
- If so, was there any evidence as to what might be driving this difference suggested by the data (e.g. differing expectations of service, repeat victimisation)?

The research project involved a mixed methodology which involved in-depth semi-structured interviews and questionnaires with both BME and non-BME communities in an area of the UK. The study was split into two parts. The first part involved 112 participants completing questionnaires. All questionnaire findings were in a similar direction and with similar differences between BME and non-BME participants. Overall, the questionnaires, revealed that BME participants were less satisfied with the police, and considered they had been treated more unfairly, were less trusting of the police and viewed the police as less helpful than nonBME participants. Following on from the questionnaires, we conducted 31 in-depth interviews with a diverse range of participants from the same area in the UK, to try and get a better understanding of their levels of satisfaction with the specific police force. 17 of the participants were from BME groups and 14 were from non-BME groups. From the semi-structured interviews, five main themes emerged:

- Police Competence - 'doing it right', including quick response times.

- Police Duty - protect public, 'aftercare' services (feedback), apologise for mistakes.

- Police Conduct - constructive, positive engagement with the public.

- Experiencing Prejudice - wider than racial or sexual discrimination with officers having negative perceptions and attitudes towards those they interact with.

- Expectations of the Police - active in communities, values in accord with wider society.

We do feel that current news and media perceptions could have influenced some of the participant's perceptions. For example, any negative stories regarding the police which had been highlighted in the media at the time, could have led to specific responses. However, we do also feel that because the study had focussed solely on one specific police force that participants would answer in an objective manner. The results from the interviews supported the idea that the police are a service, and to increase satisfaction levels, factors such as public confidence and public input into new developments, have to be considered. Furthermore, it was evident that these negative feelings were heartfelt and stem from historical issues, influenced by media reports, and more importantly negative personal encounters with the police. The lack of procedural fairness and inconsistencies in policing created mistrust amongst the participants. Consequently, participants were more concerned that police officers had the communities' best interest in mind and were willing to interact and communicate with the residents. We found that there is a need to rebuild trust and confidence between the police force and the community, and to respond to the problems that exist on the basis of mutual 
respect, clear communication and fairness. This involves police officers 'on the beat' actively engaging and talking with members of the public, not just being visible. It is also important for police officers to understand the values and culture of ethnic minorities by spending more time with them and through attending, for example, neighbourhood watch or council meetings.

There is also a need for greater awareness of the power differential between police officers and members of the public and a need to address police officers abusing the powers they have though acts of discrimination or of being 'over assertive', 'disregarding' and 'looking down on' members of the public. It involves being sensitive to the situation members of the public find themselves in and demonstrating an equal commitment to serving and protecting Black and Asian people alongside the majority non BME community. Reducing the disparity in the use of 'stop and search' procedures between BME and non-BME communities would assist with this. We argue that the following six key steps are required to increase levels of satisfaction between the police and communities they serve. These are to; (i) develop trust, particularly with BME communities, (ii) address disproportionality of experience and levels of satisfaction following engagement with the police between the different communities, (iii) be viewed as a service (rather than as a 'force'), (iv) recognise the inherent power imbalance and to always act legitimately (and be perceived as doing so) (v) ensure officers communicate effectively with the public when active in their communities, establish positive relationships and develop an understanding of the community in which they are working, (vi) develop a media strategy to promote positive messages of police activity.

\section{Background and Context}

Research has shown the over-representation of BME groups throughout all stages of the criminal justice system (Fletcher et al. 2002; Edgar and Martin, 2004) and indicated that regardless of situational or structural factors, race is one of the most consistent factors when predicting participants' attitudes towards the local police (Awan, 2012; Weitzer and Tuch, 2005; Beare, 2016). Indeed, with few exceptions, research over the years has found that race/ethnicity is one of the most significant predictors of public confidence in the police (Awan et al. 2013; Webb and Marshall, 1995: Weitzer, 2000). Findings indicate that members of minority groups have lower confidence in the police than whites (Dowler and Sparks, 2008; Gabbidon and Higgins, 2009) and also are more critical (Jefferson and Walker, 1993; Crowl, 2017).

The perceived discriminatively use of 'Stop and Search' has a profound impact on police relationships with BME communities (Renauer and Covelli, 2011), resulting in increased hostility, lack of confidence in the police and a mistrust of authority (Miles-Johnson and Pickering, 2017; Sharp and Atherton, 2007). In some areas of the UK, 8,478 stop and 
searches were conducted between January 2015 and June 2015, 2989 (35.3\%) involved BME populations (10.82 per 1000, in comparison to 2.42 per 1000 for non-BME populations).

This is significant because perceptions of the police are often formed during the first contact a member of the public has with the police (Willis and Todorov, 2006). More generally, the public are concerned not only with what the police do, but how they do their work, as they view the police as a service. They therefore expect the police to display attentiveness, reliability, responsiveness, competence, manners and fairness (Mastrofski et al. 1996; Morris, 2015).

Lind and Tyler (1988) identified three criteria that individuals use to judge whether they have been fairly treated: trustworthiness, neutrality and standing. Trustworthiness refers to the belief that the police care about them and have their best interests at mind. Neutrality is concerned with the police being fair and unbiased; displaying non-stereotypical decision making. Standing refers to being treated with respect and dignity. If all three factors are present during an encounter then it signifies to individuals that they are valued members of their social groups. This can enhance their sense of procedural fairness which in turn increases the satisfaction level. Similarly, when the police are viewed as respectful, concerned and possessing legitimate authority, the public are more likely to hold positive attitudes and comply with the law (Weitzer, 2000; Stoutland, 2001).

Social distance is also an important concept. This is the subjective perception or experience of distance from other people. It can be the distance between oneself and others, one's own and other groups' identities, unfamiliarity with others and how close a person feels to another person (Magee and Smith, 2013: 159). In respect of policing, a person with more informal and personal contact with the police is likely to feel less social distance to the police. In responding to victims of violent incidents previous research by the police force where our research was conducted found that those least satisfied with their service tend to be those between the ages of 25 and 34, from a black minority ethnic background, with those who are older than 55 or from the white community most satisfied with the service.

\section{Methods}

31 participants were recruited from the specific location where the police constabulary in question, had noted low levels of satisfaction. Once they had consented to the study and understood the relevant information, they were given a demographic questionnaire and an interview to ascertain their opinions of their experiences with the police. The participants who agreed to take part in the study, were then given a Participant Information sheet which was fully explained to them by the researcher and a consent form to sign. In choosing the sample of participants, a purposive sampling method was used. The inclusion criterion was 
based on participants who resided in the specific location in the UK where the police constabulary had received data of low levels of satisfaction.

The questionnaire was produced by combining various items from the perceptions of the police questionnaire, for example perceived confidence, visibility, overall satisfaction, and perceived police fairness. The questionnaires were disseminated to participants in the target area where the police constabulary had evidence of low levels of satisfaction. Participants were approached in various public organisations and places. Prior to beginning data collection, contact was made with these establishments to gain permission to conduct research there. Upon confirmation, participants were approached and given a brief introduction to what the research was about. Participation was entirely voluntary and all information given was confidential. They were also informed they had the right to withdraw from the study at any time. For those that were interested, they were handed an information sheet that provided them with more information on the purpose of the study. The participants were invited to ask any questions prior to signing the consent form. The questionnaire was then administered to the participants.

In order to generate and understand thoroughly the issue of satisfaction of the public towards this specific police force, the study adopted a mixed-methodology design which involved distribution of a questionnaire and face to face interviews. The purpose of collecting data in this manner, was so that we could analyse the questionnaire data alongside the experiences, attitudes and thoughts of the participants which would help enrich our qualitative part of the study. As the current study used a mixed methods approach, there were two separate data analysis strategies employed. To analyse the data gained through the demographic questionnaires, a one-way ANOVA was used and A Mann Whitney $U$ analysis was conducted to compare the responses from the different ethnic groups described. This method of data analysis was used to compare the satisfaction levels amongst victims, offenders and participants with no specific connection to the police. A oneway ANOVA was employed due to being able to compare multiple groups. A T-Test was also used to conduct more basic comparisons between two groups, such as satisfaction levels between males and females and between the broader groups of BME versus nonBME participants. To analyse the qualitative aspect of the current research, a Thematic Analysis was used (Glaser and Strauss, 1967; Braun and Clarke, 2006).

All data collection instruments used (e.g. interview questions and topic guides for interviewees) were framed and worded selectively. The interviews were conducted face to 
face and the questions, based on the topic of satisfaction with the police and were provided by the authors who also acted as moderator. Questions included:

- To what extent has your experience with the police, shaped your views about the police?

- To what extent, do you feel satisfied with the response you got from the police?

- If you had a friend that has a similar experience to yourself, would you recommend contacting the police? If not, why not? If yes, why?

- How and what would you recommend are the best methods to help the police engage with otherwise 'hard to reach' groups.

Recordings of the interviews were transcribed and thematically analysed. Participants of the interviews consented to being involved in a participant process that involved reading and clarifying a summary of the role of the interview before the process. Audio-recordings were transcribed verbatim and each participant name has been changed to ensure confidentiality and anonymity. Transcripts were read and annotated to develop themes, which are defined below. All the names of participant's names have been changed in order to ensure their anonymity. Clearly in a short study such as the present one, there is an issue of doing further research with a larger sample size that would demonstrate a more representative view of BME and non-BME communities. However, this study aimed to show a timely, snapshot of public satisfaction levels with the specific police force in question. In terms of ethnicity, we had a broad and diverse group, which was made up of different backgrounds and ethnicity. The interviewees included those from Asian heritage (3) participants, White British (14), Black (12) and Mixed race (2). The participants selected were from the specific area within the UK where the police constabulary is based.

The research project involved a mixed methodology which included a qualitative and quantitative research approach which involved in-depth semi-structured interviews and questionnaires with both BME and Non-BME communities in the area of the UK. The findings for the questionnaires mirrored those of the interviews and suggests that overall satisfaction levels in the BME participants (Mean=61.2) are significantly lower than the nonBME participants (Mean $=41.8$ ), $U=751, z=-2.79, p<.005, r=-.26$ and confidence levels are significantly lower in BME participants (Mean $=60.94$ ) than in non-BME participants (Mean = 42.52), $U=770, z=-2.64, p<.008, r=-.25$. Further analysis finds that perception of fair treatment for BME participants (Mean $=61.50$ ) are significantly lower than non-BME participants (Mean $=40.76$ ), $U=722, z=-3.03, p<.002, r=.29$ and the BME residents (Mean = 60.23 ) are significantly less trusting in the police that non-BME residents (Mean $=44.76), U$ $=830, z=-2.22, p=.026, r=-0.21$. Lastly, BME participants $(M e a n=61.07)$ find police 
significantly less helpful than non-BME participants (Mean $=42.11), U=759, z=-2.72, p$ $<.007, r=-.26$.

A self-completion questionnaire was designed which was split into two sections. Section one of the questionnaire focused on collecting demographic information such as sex, ethnicity, age and residency. Section two of the questionnaire aimed to capture views about the police. The questionnaire was produced by combining various items from the CSEW perceptions of the police questionnaire, for example perceived confidence, visibility, overall satisfaction, and perceived police fairness. A total of 15 statements were used. The items of the question were not grouped into themes however were randomly distributed throughout. Each item was scored on a 5 point likert scale (Strongly Agree, Agree, Neither Agree or Disagree, Disagree, Strongly Disagree) and participants were required to tick the box that most reflected their views. The statements in the questionnaire varied and included how confident are you about policing in your area; do the police treat ethnic minority groups fairly?, do you trust the police in your local area? And do the police understand the needs of the local community? After analysing the data, using a Thematic Analysis, five main themes emerged: Police Competence, Police Duty, Police Conduct, Experiencing Prejudice and Expectations of the Police. The results from the interviews support the idea that the police are a service, and to increase satisfaction levels other factors such as confidence and public input have to be considered.

\section{Results and Discussion}

The five main themes identified by the study are: police competence, police duty, police conduct, experiencing prejudice and expectations of the police. In addition to identifying the main themes, some participants shared details of the grounds for their contact with the police, for example, one participant had the police attend a road traffic accident in which he was involved in.

\section{Police Competence}

The competence of the police and their ability to be able to do the job for which they are employed appeared to be one of the most important factors to the participants. Mastrofski et al. (1996) highlighted this as being one of the major components the public are concerned with when they are receiving a service from the police. Mastrofski et al. (1996) stated that the public perceive police performance in terms of tangible results that mean something to the public, rather than statistics that are of no use to them. This may be in terms of giving the public the correct information once they have been in contact with the police. Gau (2010) studied the relationship between performance based assessments and police performance, one aspect of this was the ability of the police to manage serious crime. By being able to 
demonstrate that they were able to manage serious crime, Gau (2010) concluded that the public's perception of the competence of the police would have a consequential effect on later contact with the police.

Another issue raised under the theme of police competence, is the idea that police response times are an indication of how well the police are performing in the community. One participant highlighted how if the police are viewed to attend an incident quickly then they are more likely to be seen favourably, whilst another participant continued to criticise the police for their lack of response and how it affected them. Bradford et al. (2009) argue that the public perception of the police is dependent on the public's idea of what constitutes policing practices. Jackson and Sunshine (2007) state that public opinion may be the result of 'lay' opinions in to police procedure and the public wanting the police service to be more client centred. The lack of public acknowledgement of what constitutes an emergency and therefore what warrants a prompt emergency response from the police was raised by a number of participants.

“...I feel that the police do an alright job...” Participant 1, line 4.

"...Gave us a crime reference number and that. They made sure we knew what we were doing and how to follow it up etc...." Participant 8, line 9

\section{Police Duty}

Another main theme the participants discussed was the 'duty' of the police when in contact with the public. Weitzer and Tuch (2005) considered misconduct as a precedent to the public having lower levels of satisfaction with the police. This meant that if the public experienced wrong doing by the police in terms of how they carry out their jobs, which is linked to police competence, but also in terms of how they behave towards members of the public, then confidence levels will suffer as a result. This was highlighted by participants who stated that not all members of the public are treated the same, and that the public expect the police to carry out their duty in terms of protecting them. Furthermore, some participants felt that the 'treatment' they received from the police was below the standard that was expected, for example, participants felt that not receiving any feedback about an incident was not acceptable. Another participant stated how she had to go and find the police when she needed assistance, when she felt that there should have been more police officers available. Although this was one issue that was raised by several participants, centred on the premise that more police officers would make members of the public feel safer, one method that has been used as a proxy for an increased presence of police officers in communities is the use of CCTV cameras. Awan (2012) demonstrated that the use of CCTV cameras actually had an adverse effect with members of the public, as the 
members of that study felt they their privacy was being invaded as they felt they were being watched for any wrong doing, and rather than being used as a method of surveillance for protection.

“...Not all the police treat the public the same..." Participant 1, lines 9-10

“...Not only that, but the aftercare I received from the people at the station wasn't exactly great either..." Participant 2, lines 33-35

The presence of 'visible' police also created mixed messages for many of the participants. Some of the participants felt that the presence of police officers made them feel safer whilst others felt uncomfortable. Some participants felt that police visibility required further engagement and work in interacting with the public as opposed to 'disassociating themselves from the people they are employed to serve'.

"I wouldn't just say police being visible but there's big difference between walking up and down the street and going and interacting with people, talking to people, finding out what is going on in the area, going to the neighbourhood watch meetings, going to the council meetings or something like that."

(Kelly, White, Female, 18-24)

Some of the accounts suggested that the public are not listened to. On one occasion a participant had to rely on the CCTV to inform police officers that he was telling the truth. Many of the participants felt a need to complain about their treatment or experience however there was a general belief that the complaints would 'fall on death ears' and 'nothing would be done'. In one example when a complaint was made and there was an unsatisfactory outcome.

"No, I never and you know what they didn't even give me anything to say I had made a complaint, there response to me was, the guy that took my details said, when you go in there speak to the guy because his done first aid, and I went in there and told him and I couldn't move my arm properly for a bit so I said his proper hurt my shoulder and its stiff and this is the shoulder that I dislocated so his gone to me 'Mate, I've dislocated my shoulder before and it didn't hurt that much so your over reacting' that was his reply and that was it."

(Dwayne, Black, Male, 34-44)

On various occasions many participants highlighted that the media played an important part in influencing people's view of the police. Participants felt that the media did not help as it 
tended to report on negative events such 'White officer seen man handling black man to the floor' as opposed to highlighting the positive things the police do.

\section{Police Conduct}

As noted earlier, the impression the public get of the police during the first contact is one of the most powerful predictors of future satisfaction with the police. Willis and Todorov (2006) have suggested that it takes as little time as $100 \mathrm{~ms}$ to form a first impression of a person, which is what people base their opinions on. Some of the participants discussed how they felt that some police officers had been rude to them or felt as if they had no time for them and subsequently appeared to be disinterested with the participant and their requests. As it is likely that most of the participants will come in to contact with a police officer in some form, then the police service have to ensure that the way in which the police officers conduct treat members of the public equally. Furthermore, the conduct of the police officer towards a member of the public depends in part on the conduct of the member of the public. Reisig and Parks (2000) stated that the member of the public is in actual fact more likely to be disrespectful and rude towards the police officer than vice versa. In addition to this, the conduct of the police is something that is more difficult to control in comparison to factors such as competence, as competence is measured in terms of how well a person can perform their job by following a set of rules. Whereas conduct is an individual construct and will therefore be affected by individual factors that are not able to be controlled. It is possible for police officers to be trained in how to approach situations and members of the public, training is ineffective when trying to amend individual attitudes or beliefs.

"... Their behaviour towards me changed. It went from being polite and reasonable to pushy..." Participant 20, lines 12-13

It is a matter of some concern that on occasions it seems that the police service had exerted their force on individuals and abused their powers of authority. This has been identified in the discourse where individuals feel that excessive force has been used and they have been 'roughed up'.

"No they were very forceful. They restrained me on the pavement and then tied me to a stretcher and they knelt on, like in my back to keep me in place literally there was a guy well officer kneeling in my back to hold me down which probably wasn't the way to do it really. It was really painful and I was left with a bruise."

(Robert, White, Male, 24-34) 
"His come out and his twisted up my arm so the next guys come over and l'm saying 'look his hurting my arms' you know what I mean, look his hurting my arms and I was wrestling with him back saying you're hurting my arms and the more I wrestled with him the more he pushed my arm up in my back, you get me."

(Andrew, Black, Male, 34-44)

There is evidence that suggest the participants are also unsure of the role of the police and feel that it's now developed into a situation where people's perceptions of them has changed.

"Which is why you need to have them about more generally so people can recognise as I think well it's police as well, because they may feel they are only there to solve crimes not there for being community support people really, they are there for crime busting and we now have the perceptions that we only see them when things are bad so we need to kind of change that perception and turn it around so the police are people we can speak to if you need help in some way."

(Mark, White, Male, 25-34)

\section{Experiencing Prejudice and Issues of Trust}

Not all of the BME participants stated that they felt they had been subjected to prejudice from the police, however, some of the non-BME participants highlighted their experiences of feeling like they were being judged based on the situation they found themselves in with the police or because of the police perception of them. These participants spoke of how they felt that the police had judged them and how they subsequently felt prejudice from the police. Salisbury and Upson (2004) suggest that members of the public that are from BME groups are less likely to report crime as they feel that it will not get the same response from the police as a crime that has been reported by a non-BME member of the public, even if they have not experienced racial prejudice prior to reporting a crime. The fact that members of the public have a lack of confidence in the police to treat their demands with equality has meant that the police have to accommodate the public's lack of faith and confidence before addressing any issues of racism (Foster et al. 2005).

“... The way I was treated made me feel like I was a criminal...” Participant 2, lines 1-2

“...I felt like I was being prejudged and they made me feel guilty...." Participant 3, lines 1-2

Many of the participants described situations that implied a lack of trust and confidence in the police service. This has manifested itself in many ways and a number of BME 
participants felt that the police force are 'pretty useless' and 'don't expect much from them' in times of need. In some reports individuals spoke about seeking help from family members or friends prior to contacting the police.

"I'll tell you this, when my house was getting burgled the police were not the first people on the scene and I called them first! I called my parents and they came from 20 minutes away and the police station is down the road... How can you even trust people who take their time to arrive when you're in danger?"

(Sally, Black, Female, 18-24)

For one participant, he felt as though the police service was run like a business. He explained that he feels to be a police officer you 'have to be judgemental' and it's a system that works based on targets.

"Think of it this way any job in some way is about hitting targets, making money, some form or productivity that's how business works, and so therefore I have no doubt that the force have their KPI's."

(John, Black, Male, 24-24)

None of the participants had been victims of the stop and search procedures. However, some had been stopped and accounted for. For them they felt that as though the police were not 'doing anything constructive' and were 'looking for trouble'.

"Police officers stop you without any real justifiable reason; it's just a broad brush approach to finding a criminal. Like 'Oh let's just stop them because they might be up to something or they look a certain way'. There is no defined approach to what they are actually looking for."

(John, Black, Male, 24-34)

\section{Expectations of the Police}

During the course of the interviews the participants were asked what they would have liked from the police when they had contact with them. Responses to this question varied from the police response rate and trusting the police to do their jobs in line with their own societal beliefs. This was demonstrated by participants stating that if they witnessed the police being involved in any scandals or racism then it would affect their opinion and confidence in the police. The participants had many expectations of the police including police officers being 
more proactive and active in communities. Mastrofski et al. (1996) stated that having a proactive police force as opposed to a reactive police force is likely to be received better by the public, as they are able to see the police attempting to provide a service for the public. Hohl et al. (2010) conducted a study whereby they attempted to seek the differences between informed and uninformed members of the public and their opinions of the police and the service they provide. Hohl et al. (2010) found that by providing leaflets to the public, and by attempting to keep the public informed of the police's agenda, therefore making the police appear proactive in community policing, that it had a an important impact on the satisfaction levels of the public. In addition to having certain expectations of the police, the study was interested in whether or not the participants would report incidents to the police. A number of the participants stated that they would recommend people contact the police, not because of how they have handled their current situation, but because that is what 'they would do.' One participant stated that it is because it is what you are supposed to do. Mason et al. (2014) state that the police are the only agency that is able to ensure your safety, and as a result we accept a degree of limitation of our rights, and so forgo some of our expectations.

"...If I were in trouble l'd recommend calling the police as that's what you're supposed to do...." Participant 1, lines 22-23

“...Bit more action...” Participant 7, line 3

“...But I'm not sure what we were expecting to be honest...” Participant 8, lines 2-3

On two occasions participants stated that they would value police officers who were honest and 'fit enough'. A few participants stated they would rather have 'cops that do their job, that don't stereotype, that treat us as equals and that's what we want'. Some participants highlighted that they would want the police not only to do a good job but to treat the public with respect.

"I think at the same time there should be more black people going for it but as a race of people that's been treated badly by the police why would you join something that's been treating you so bad, your parents so bad, your grandparents so bad over the year and I feel that's the general consensus for black people as a whole."

(Black, Male, 24-34)

Furthermore, there was a fear of institutional racism and a lack of career development has deterred people from considering and beginning the application process. One participant felt that working as a police officer was not a respectful career and referred to policemen being 
'puppets' and they do not 'have a mind of their own'. Two participants feared they would experience high levels of oppression.

"Yes, a house nigger we shall call it, a house nigger police, you know. Bullied in the work place, doing what they say, not being valued, treated like shit, walked all over, not getting that big money. You catch my drift."

(Andrew, Black, Male, 34-44)

Participants were asked how the satisfaction gap can be improved between BME communities and the police, as many participants referred to it as the 'million dollar question'. The responses were extremely varied from each account. Some participants felt that it requires 'a stage that is beyond improvement and is not going to get any better' whereas others felt to make an active change you would need to start from the beginning as explained below:

"I feel like if they wanted to improve things they would have to start with children. So they would have to start by going into schools and I feel like they don't, like they used to and what they are to be teaching the children needs to constant to build a relationship with them." (Lisa, Black, Female, 18-24)

Some participants felt as though the problem could be fixed internally.

"It needs another Black or Asian person to be the police force that can educate the white officers of what is happening within the local community and find ways of how to best reach out to our Black and Asian people." (Black, Male, 55)

In addition to this, previous research has found that by keeping members of the public informed and up to date with the police service, and their current agenda, that the public are more receptive to new initiatives introduced by the police service (Innes and Fielding, 2002). Mason et al. (2014) suggests that informing members of the public increases confidence in the police, but more importantly it stabilises the perception of confidence in those members of the public, so they are less likely to feel the police are less competent when their efficiency is called into question. Finally, as the study is concerned with policing local communities, it is important to remember that members of the community will respond positively to being included in police procedure deliberations and audits. Mastrofski et al. (1996) have suggested that the public feel that outside agencies should be included in policy making and reviews to ensure that not only is there no biases, but that as the public are the ones being governed by the police, that the policies that are enforced are fair and reflect the opinions of the public and not just the police service. 


\section{Conclusion}

The main objective of this research was to examine the perception and satisfaction of a police force in a part of the UK. Given the small sample size, care needs to be taken when interpreting the findings. The results are best thought of as ideas which merit further consideration, which as separate entities highlight some of the difficulties faced by the participants, however when considered together pose a challenge to a police service that must rebuild bridges between the community and themselves to ensure the longevity and co-operation of the community. Previous research have shown that race and ethnicity are important in determining people's satisfaction and confidence with the police, with ethnic minorities having the lowest rating of satisfaction and generally holding unfavourable attitudes towards the police (Brown and Benedict, 2002; Webb and Marshall 1995; Skogan 2005). There were significant differences in the level of trust ethnic minorities have of the police and there was a significant difference in how helpful ethnic minorities perceived the police to be.

Consequently, the findings illustrate that BME communities perceived themselves to be treated less fairly than others. Victimisation experiences such as stop and accounts and being pulled over tended to reduce the confidence in the police. Bowling and Phillips (2002) found that the disproportionate amount of stop and search are recognised by all ethnicities. The nature of the interactions between ethnic minorities and the police highlight some concerns. Individuals reported incidents where the police service in question, displayed aggression, disrespectful, stereotypical attitudes and in one account racism. These interactions often encouraged individuals to avoid contact with the police for fear of being wrongly accused or mistreated. It was not confirmed whether these actions were conducted solely by white officers so we are unable to conclude that any negative experience was racially motivated. In light of the current topic, negative contact can damage the views of the community and also re-enforce negative pre-conceptions of the police (Skogan, 2006).

In 2015/16, Her Majesty's Inspectorate of Constabulary and Fire \& Rescue Services (HMICFRS) the organisation responsible for assessing the effectiveness of the police force commissioned Ipsos MORI (2016) to undertake a survey of public perceptions of policing in England and Wales. Interestingly, as our findings also suggest, they found positive levels of public satisfaction based on policing being more visible and when local policing actively engaged with the communities they serve. However, they did also find low levels of satisfaction based upon some participants mainly from the black and ethnic minority groups who felt unsafe and thought that crime or anti-social behaviour was a problem. 
Consequently, it is important for the police not only to have a presence in the community but to be seen positively interacting with community members. Further to this, one account highlighted the importance of knowing specific officers that worked in the neighbourhood. For this person, seeing a familiar face would allow a relationship to be built as they would be more inclined to say hello as opposed to walking past. Stanko (2009) argue that direct communication can improve confidence and influence opinion. In regards to the recruitment of ethnic minority officers, many respondents felt that it would be beneficial and comforting to have more ethnic officers as they feel they would be able to relate to them better. They also felt the police force would have a better understanding of their cultural and traditional needs. A number of participants from BME communities, stated they would not work for the police, despite some of them considering it as an option at a younger age. A number of people regarded the police service to be corrupt, uncaring, unhelpful and useless. There was clear evidence that suggests many believe institutional racism still occurs within the force and that ethnic minorities are at a disadvantage to their white counterparts.

Correspondingly, Mason et al. (2014), highlights there are several reasons for the disinterest in a career in the police force and as the accounts suggest many feel they will have difficulty climbing up the ladder to higher ranks and this is one of many reason why there is a reluctance to apply. Similarly, the findings of Holdaway (1996) who explored the racial relations within the police found that the alleged perceptions and beliefs act as a barrier for many ethnic minorities. The results presented above indicate that the participants felt they are not being treated fairly and are being stereotyped. All of these factors combined illustrate how individuals might feel that they are not valued members of the community, which in turn decreases their perception of procedural fairness which then results in lower satisfaction (Lind and Tylers 1988).

From a policy perspective, the findings reported here suggest improving the satisfaction levels of BME communities toward the police requires the improvement of current police practice in dealing with people from an ethnic minority background. Many participants felt that the reasons for being stopped and searched or stop and accounted for are not conclusive. Therefore, it is recommended that the process of stop and search needs to be reviewed and a more transparent policy developed. If this issue is not address it could lead to even more damaging effects for the BME community and the failure to gain this legitimacy has serious consequences and would lead communities to be more challenging of police authority (Tyler, 2006). In many ways the police need the support from citizens and want to be considered legitimate in the community. Many respondents expressed that this satisfaction gap that is apparent between the BME community and the police cannot be fixed 
unless there is co-operation and efforts from both parties. Respondents suggest that this gap can be fixed but it needs to begin with the younger generations. Entering into schools and educating the youth about the police and what they do would be a foundation. However, for those that believe that early intervention is the key, they also argue that it should recognise that unjustified actions by the police will continue to cause dissatisfaction. Other participants believe that the police force 'set the tone' for how the community responds and therefore consideration needs to be taken when the police are communicating with the public. Once the barriers of communication are tackled, it allows for a trusting relationship to be built. In turn this trusting relationship may instil confidence and satisfaction within the community.

\section{References}

Awan, I., Blakemore, B. and Simpson, K. (2013) 'Muslim Communities Attitudes towards and recruitment into the British Police Service', International Journal of Law, Crime and Justice, 41 (4): $421-437$.

Awan, I. (2012). The impact of policing British Muslims: a qualitative exploration. Journal of Policing, Intelligence and Counter Terrorism, 7(1), 22-35

Beare, M. (2016) What matters in policing? Change, values, and leadership in turbulent times, Police, Practice and Research: An International Journal, 18 (2): 207-209.

Bowling, B., and Phillips, C. (2002). Racism, Crime and Justice. Harlow: Pearson Education: 139.

Bradford, B., Jackson, J., and Stanko, E. A. (2009). Contact and confidence: revisiting the impact of public encounters with the police. Policing \& society, 19(1), 20-46.

Braun, V., \& Clarke, V. (2006). Using thematic analysis in psychology. Qualitative research in psychology, 3 (2), 77-101.

Brown, B., \& Reed Benedict, W. (2002). Perceptions of the police: Past findings, methodological issues, conceptual issues and policy implications. Policing: An International Journal of Police Strategies \& Management, 25(3), 543-580.

Crowl, J. (2017) The effect of community policing on fear and crime reduction, police legitimacy and job satisfaction: an empirical review of the evidence, Police, Practice and Research: An International Journal, 18 (5): 449-462. 
Dowler, K., \& Sparks, R. (2008). Victimization, contact with police, and neighbourhood conditions: reconsidering African American and Hispanic attitudes towards the police. Police Practice and Research: An International Journal. 9(5), 395-415.

Edgar, K., \& Martin, C. (2004). Perceptions of Race and Conflict: Perspectives of Minority Ethnic Prisoners and of Prison Officers. Home Office Online Report 11/04. Retrieved from http://library.college.police.uk/docs/hordsolr/rdsolr1104.pdf

Fletcher, H., Providence, B., Mulixidwa, J. and Asafo-Agyei, H. (2002). Race, Discrimination and the Criminal Justice System. Retrieved from www.blink.org.uk/abpoa.htm.

Foster, J., Newburn, T., \& Souhami, A. (2005). Assessing the impact of the Stephen Lawrence inquiry. London: Home Office.

Gabbidon, S. L., \& Higgins, G. E. (2009). The role of race/ethnicity and race relations on public opinion related to the treatment of blacks by the police. Police Quarterly, 12, 102-115.

Gau, J. M. (2010). A longitudinal analysis of citizens' attitudes about police.Policing: An International Journal of Police Strategies \& Management, 33(2), 236-252.Glaser, B., \& Strauss, A. (1967). The Discovery of Grounded Theory. Chicago: Aldine

Hohl, K., Bradford, B., \& Stanko, E. A. (2010). Influencing Trust and Confidence in the London Metropolitan Police Results from an Experiment Testing the Effect of Leaflet Drops on Public Opinion. British journal of criminology, 50(3), 491-513.

Holdaway, S. (2010). Understanding 'trust' and 'confidence': Problems within and out with constabularies. Policing: A Journal of Policy and Practice, 4(3), 258-264.

Home Office (2013). Police Workforce, England and Wales

https://www.gov.uk/government/publications/police-workforce-england-and-wales-31-march2013/police-workforce-england-and-wales-31-march-2013

Innes, M., \& Fielding, N. (2002). From community to communicative policing: 'signal crimes' and the problem of public reassurance. Sociological Research Online, 7(2).

Ipsos MORI (2016) Public views of policing in England and Wales 2015/16, A report for HMIC http://www.justiceinspectorates.gov.uk/hmicfrs/publications/public-views-policingengland-2015-16/

Jackson, J., \& Sunshine, J. (2007). Public Confidence in Policing A Neo-Durkheimian Perspective. British journal of criminology, 47(2), 214-233. 
Jefferson, T., \& Walker, M. A. (1993). Attitudes to the police of ethnic minorities in a provincial city. British Journal of Criminology, 33, 251-266.

Lind, A. E., \& Tyler, T. R. (1988). The Social Psychology of Procedural Justice. New York: Plenum Press.

Magee, J. C., \& Smith, P. K. (2013). The Social Distance Theory of Power. Personality and Social Psychology Review. 17(2), 158-186.

Mason, D., Hillenbrand, C., \& Money, K. (2014). Are Informed Citizens More Trusting? Transparency of Performance Data and Trust Towards a British Police Force. Journal of business ethics, 122(2), 321-341.

Mastrofski, S. D., Snipes, J. B., \& Supina, A. E. (1996). Compliance on demand: The public's response to specific police requests. Journal of research in Crime and delinquency, 33(3), 269-305

Miles-Johnson, T., and Pickering, S. (2017) Police recruits and perceptions of trust in diverse groups, Police, Practice and Research: An International Journal (Online)

http://dx.doi.org/10.1080/15614263.2017.1364162

Morris, C. (2015) An international study on public confidence in police, Police, Practice and Research: An International Journal, 16 (5): 416-430.

Reisig, M. D., \& Parks, R. B. (2000). Experience, quality of life, and neighborhood context: A hierarchical analysis of satisfaction with police. Justice quarterly, 17(3), 607-630.

Renauer, B. C., \& Covelli, E. (2011). Examining the relationship between police experiences and perceptions of police bias. Policing: An International Journal of Police Strategies \& Management, 34(3), 497-514.

Salisbury, H., \& Upson, A. (2004). Ethnicity, victimisation and worry about crime: findings from the 2001/02 and 2002/03 British Crime Surveys. Home Office. Research, Development and Statistics Directorate.

Skogan, W. G. (2005). Citizen satisfaction with police encounters. Police Quarterly, 8(3), 298-321.

Skogan, W. G. (2006). Asymmetry in the impact of encounters with police.Policing \& Society, 16(02), 99-126. 
Stanko, E. A. (2009). Improving policing through research. Policing: A Journal of Policy and Practice, 3(4), 306-309.

Stoutland, S. E. (2001). The multiple dimensions of trust in resident-police relations in Boston. Journal of Research in Crime and Delinquency, 38(3), 226-256.

Tyler, T. R. (2006). Why people obey the law. Princeton University Press.

Webb, V., and Marshall, C. E. (1995). The relative importance of race and ethnicity on citizen attitudes toward the police. American Journal of Police, 15, 45-66.

Weitzer, R., \& Tuch, S. A. (2005). Determinants of public satisfaction with the police. Police Quarterly, 8(3), 279-297.

Weitzer, R. (2000). White, Black, or blue cops? Race and citizen assessments of police officers. Journal of Criminal Justice, 28, 313-324.

Willis, J., and Todorov, A. (2006). First impressions making up your mind after a 100-ms exposure to a face. Psychological science, 17(7), 592-598. 